
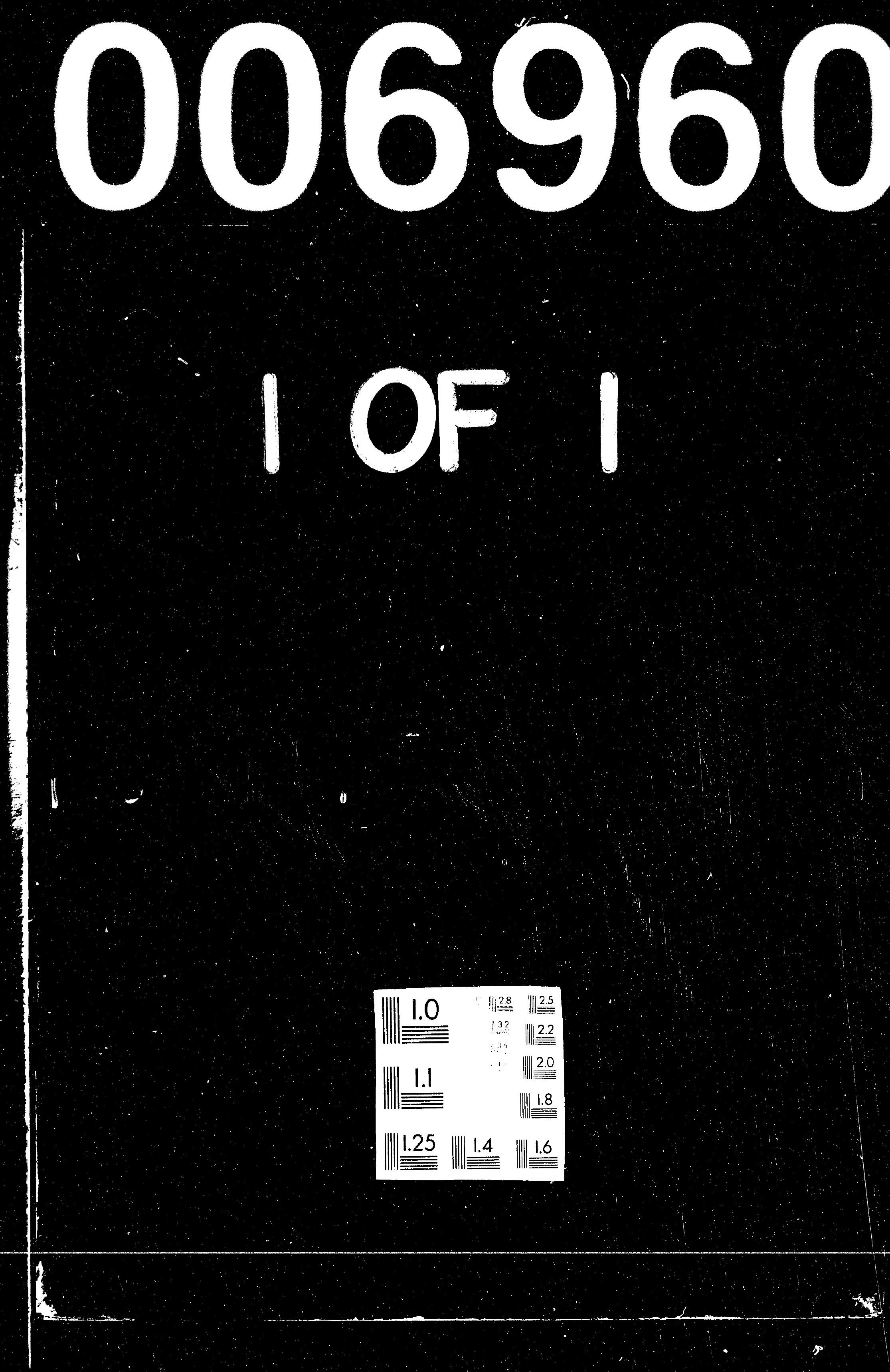


\section{Architecture and Functional Decomposition of the SENSE Function}

by A.C. Segal* and G.H. Chisholm

Environmental Assessment and Information Sciences Division,

Argonne National Laboratory, 9700 South Cass Avenue, Argonne, Illinois 60439

December 1992

Work sponsored by United States Department of Cefense

Segal is affiliated with the Iniversity of Illinois at Chicago. 


\section{CONTENTS}

ACKNOWLEDGMENTS $\ldots \ldots \ldots \ldots \ldots \ldots \ldots \ldots \ldots \ldots \ldots \ldots \ldots$

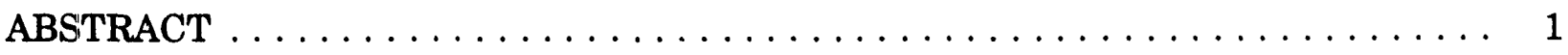

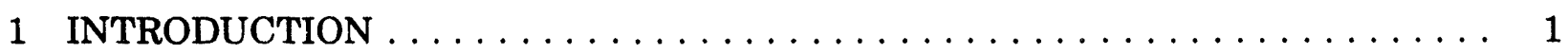

2 FLOW NET REPRESENTATION OF THE SENSE MODEL $\ldots \ldots \ldots \ldots \ldots \ldots$

2.1 Advantages of Flow Net Representation $\ldots \ldots \ldots \ldots \ldots \ldots \ldots \ldots \ldots 2$

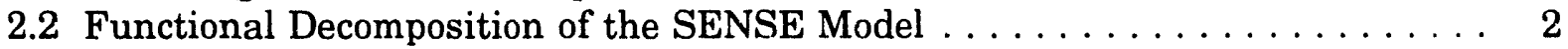

3 USE OF THE HIERARCHICAL DECOMPOSITION $\ldots \ldots \ldots \ldots \ldots \ldots \ldots$

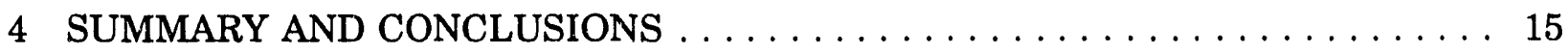

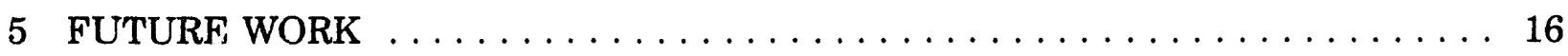

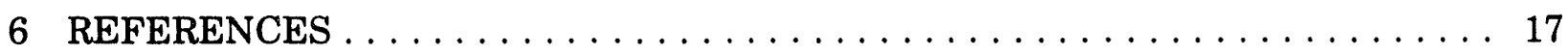

\section{TABLES}

1 Comparison of the ACQUIRE and PROCESS Subfunctions $\ldots \ldots \ldots \ldots \ldots \ldots$

2 Properties of Transition: False Alarms and Missed Detections for

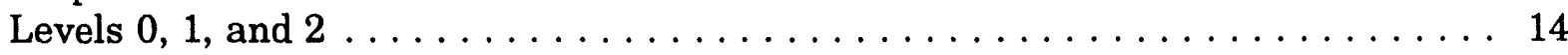

\section{FIGURES}

1 GPALS: Functional Allocation $\ldots \ldots \ldots \ldots \ldots \ldots \ldots \ldots \ldots \ldots \ldots \ldots \ldots \ldots \ldots$

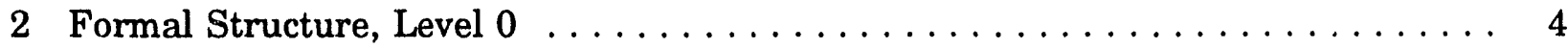

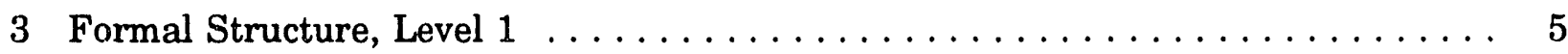

4 Formal Structure, Level 2: ACQUIRE $\ldots \ldots \ldots \ldots \ldots \ldots \ldots \ldots \ldots \ldots$

5 Formal Structure, Level 2: PROCESS $\ldots \ldots \ldots \ldots \ldots \ldots \ldots \ldots \ldots \ldots \ldots$

6 Formal Structure, Level 3: (a) Geometric Mapping for ACQUIRE and

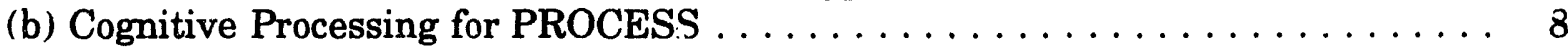

7 Formal Structure, Level 3: (a) Sensor Response for ACQUIRE and (b) Feature/Matched Filter for PROCESS $\ldots \ldots \ldots \ldots \ldots \ldots \ldots \ldots \ldots, 9$ 


\section{FIGURES (Cont.)}

8 Formal Structure, Level 3: (a) Sensor Distortion for ACQUIRE and

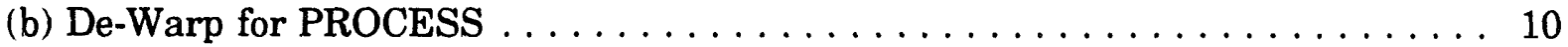

9 Formal Structure, Level 3: (a) Sensor Noise for ACQUIRE and (b) Preprocess/Filter Data for PROCESS 


\section{ACKNOWLEDGMENTS}

This work was supported in part by the Strategic Defense Initiative Organization, Office of the Secretary of Defense, under PMA-2304, and in part by the National Security Agency, V31, under MOD 708992. 


\title{
ARCHITECTURE AND FUNCTIONAL DECOMPOSITION \\ OF THE SENSE FUNCTION
}

by

\author{
A.C. Segal and G.H. Chisholm
}

\begin{abstract}
Three functions (i.e., SENSE, PLAN, and EXECUTE) make up the essential functionality for the battle management/command, control, and communications element of the Global Protection Against Limited Strike system. This report focuses on issues related to the SENSE function to support the complexity management analysis of this element.

In this analysis, a multilayered decomposition is developed from a high-level model. This model depicts energy from the environment as input and target vectors as ouput. This model can be decomposed into subfunctions, which are subsequently further decomposed. The hierarchy for three layers of decomposition is described. This structure provides a basis for careful analysis of essential properties (e.g., false alarms, missed detections).
\end{abstract}

\section{INTRODUCTION}

This report expands upon a study of the battle management/command, control, and communications element of the Global Protection Against Limited Strike (GPALS) system (Chisholm 1992). Specifically, this report focuses on the SENSE function in the GPALS architecture. A flow net representation is used to study some of the subfunctions of the SENSE function (Winter et al. 1991). A more formal system is derived that can be analyzed with regard to the effects of false alarms, missed detection targets, data dependency, and fault tolerance (compliance of the system with the specified designs of the GPALS system). 


\section{FLOW NET REPRESENTATION OF THE SENSE MODEL}

The model developed in Chisholm (1992) treated SENSE at an abstract level to keep reasoning about alternative GPALS models tractable. Nevertheless, a more detailed description of the SENSE function is essential for understanding its properties and estimating the system's performance. $A$ flow net representation is used to develop such a description.

The basic components of the flow net representation are listed below. Descriptions of each component refer to the figures included in this report.

- Transitions. Transitions are represented by horizontal black bars and include a name that describes the functionality of the transition. Transitions can occur only when all the places and inputs are ready and the output of the transition readies the next state.

- Places. Places are represented by circles that contain text related to the type of data or data structure (i.e., tokens) processed by the transition. Each place is some form of data (e.g., energy, analog data, or digitized data).

- Inputs to transitions. Inputs to transitions are represented by lines with arrows and by text that describes the inputs from the sensor and the environment being sensed.

\subsection{ADVANTAGES OF FLOW NET REPRESENTATION}

A flow net is a directed graph extend from Petri net theory (Peterson 1981). One advantage of flow net representation is that it can easily be translated into first-order predicates for use in automated reasoning systems. These systems can probably be used to determine properties of data dependency, fault tolerance, and robustness and to synthesize, designate, verify, and validate specifications.

Another advantage of flow net representation is that it allows for a hierarchical representation of SENSE on the basis of system functionality rather than hardware or algorithm flow. Thus, it is a more natural architecture for system-level analysis. Furthermore, an analysis of the hierarchical decomposition of the SENSE function reveals the symmetry inherent in the SENSE function.

\subsection{FUNCTIONAL DECOMPOSITION OF THE SENSE MODEL}

Figure 1 shows the relationship of the SENSE function in the sense-plan-execute triad developed in Chisholm (1992). This report constructs the various levels of the flow net (see Figures 2-9). As one moves down these levels, each process is hierarchically decomposed 
Legend

STP Sensor Tasking Plan

WTP Weapon Tasking Plan

ECD Element Control Directive

$\bigcirc$ SENSE $\triangle$ Plan $\bigcirc$ Execute
One Tail/Head Number

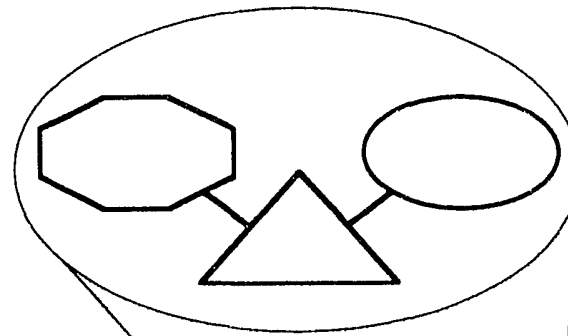

SENSE Platform

(May Be Multisensor)

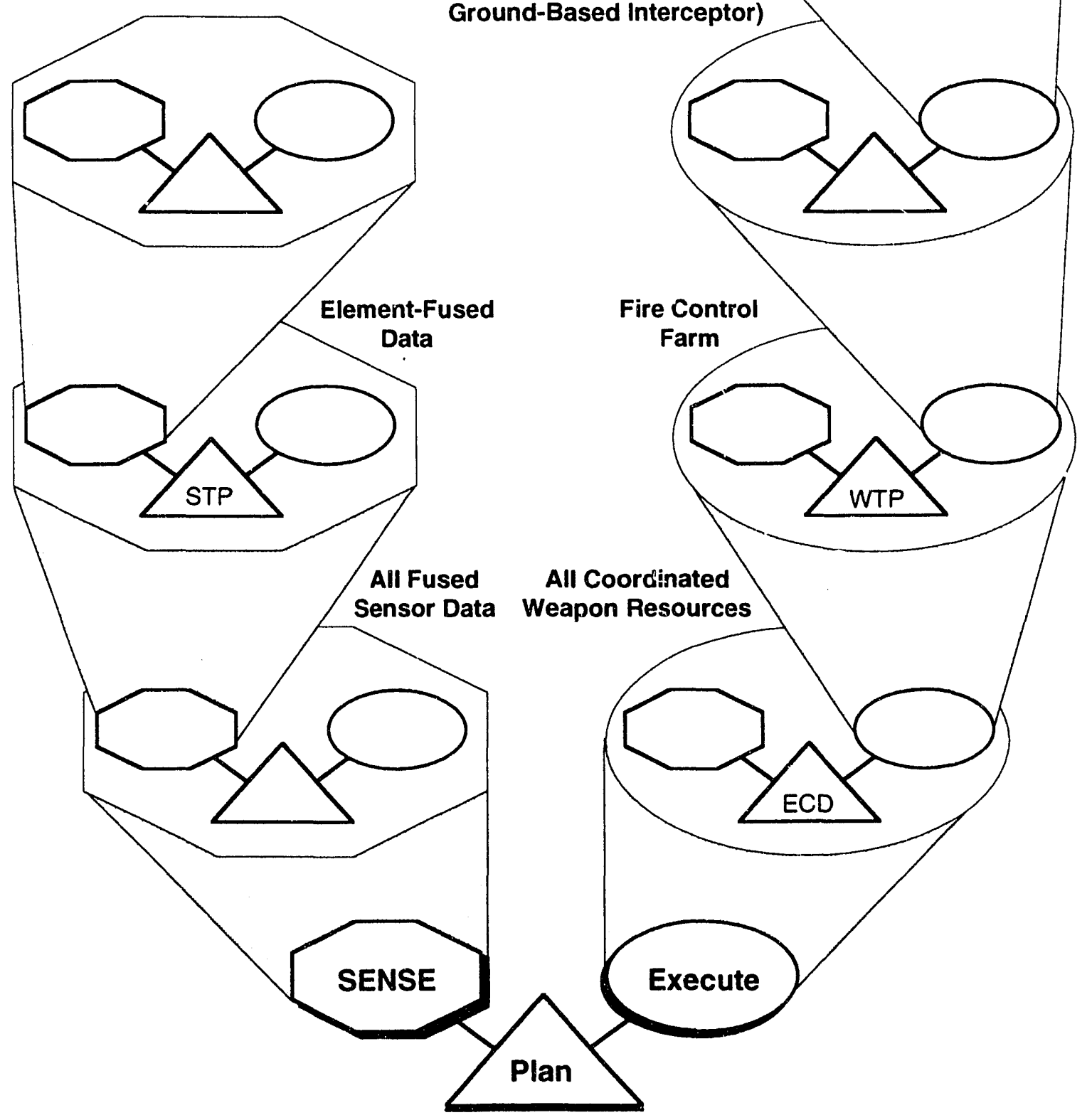

FIGURE 1 GPALS: Functional Allocation 


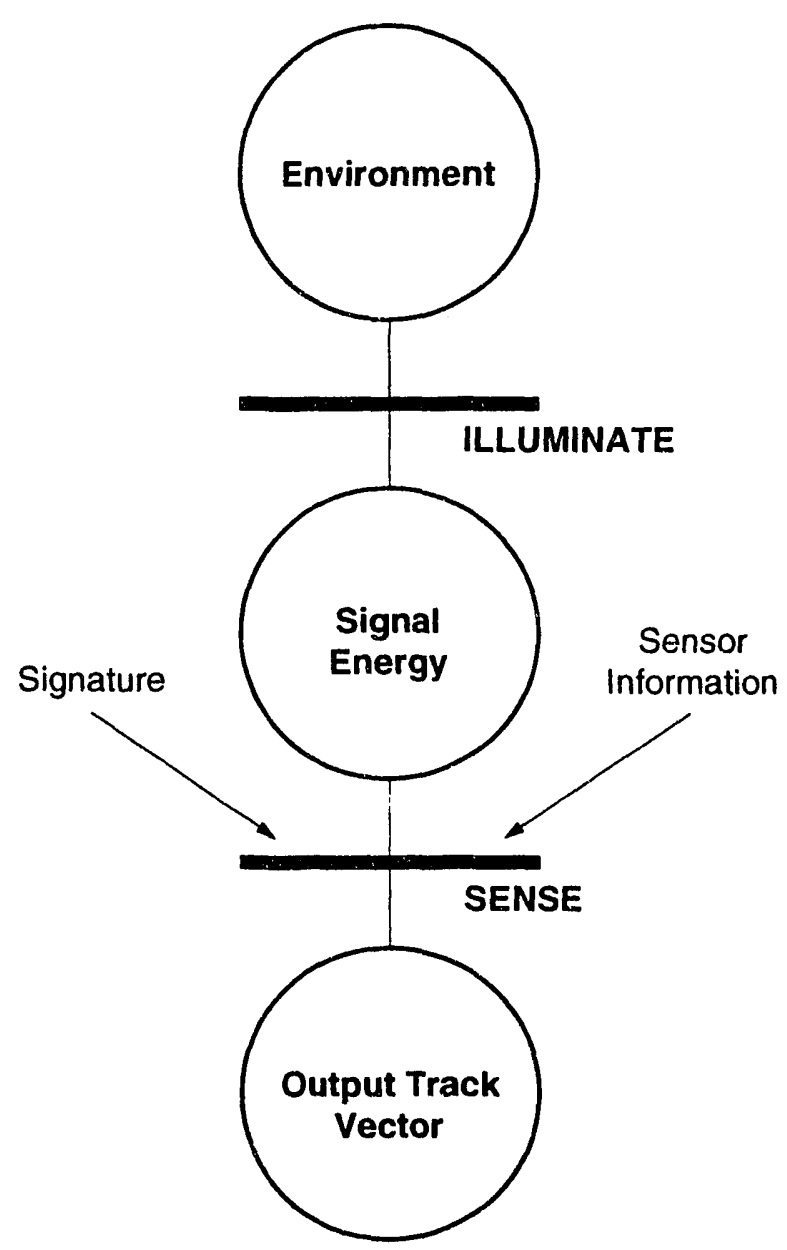

FIGURE 2 Formal Structure, Level 0

until a leaf node (i.e., the farthest distance from the primary node, no matter which path is followed) is reached. Such a node is typically a subroutine module or a physical or hardware property or process.

At level 0 of SENSE (see Figure 2), which is the highest level, the state of the environment is illuminated to produce signal energy. The signal energy is combined with some knowledge of the signature of the target to then produce an output track vector. This vector consists of location, velocity, and other track information of one or more sensed targets. The signal energy can be either in the electromagnetic spectrum (radio/optical/infrared) or in acoustic bands.

At level 1 (see Figure 3), SENSE is decomposed into two subfunctions: an acquisition function (ACQUIRE) and a processing function (PROCESS). AQUIRE obtains data and maps signal energy into an analog or digital signal. PROCESS uses information about the target signature to produce the output track vector. At this level, the PROCESS subfunction could be a tracking algorithm that uses previous tracking information to update current output vectors. This subfunction is represented by the dashed feedback loop shown in Figure 3. 


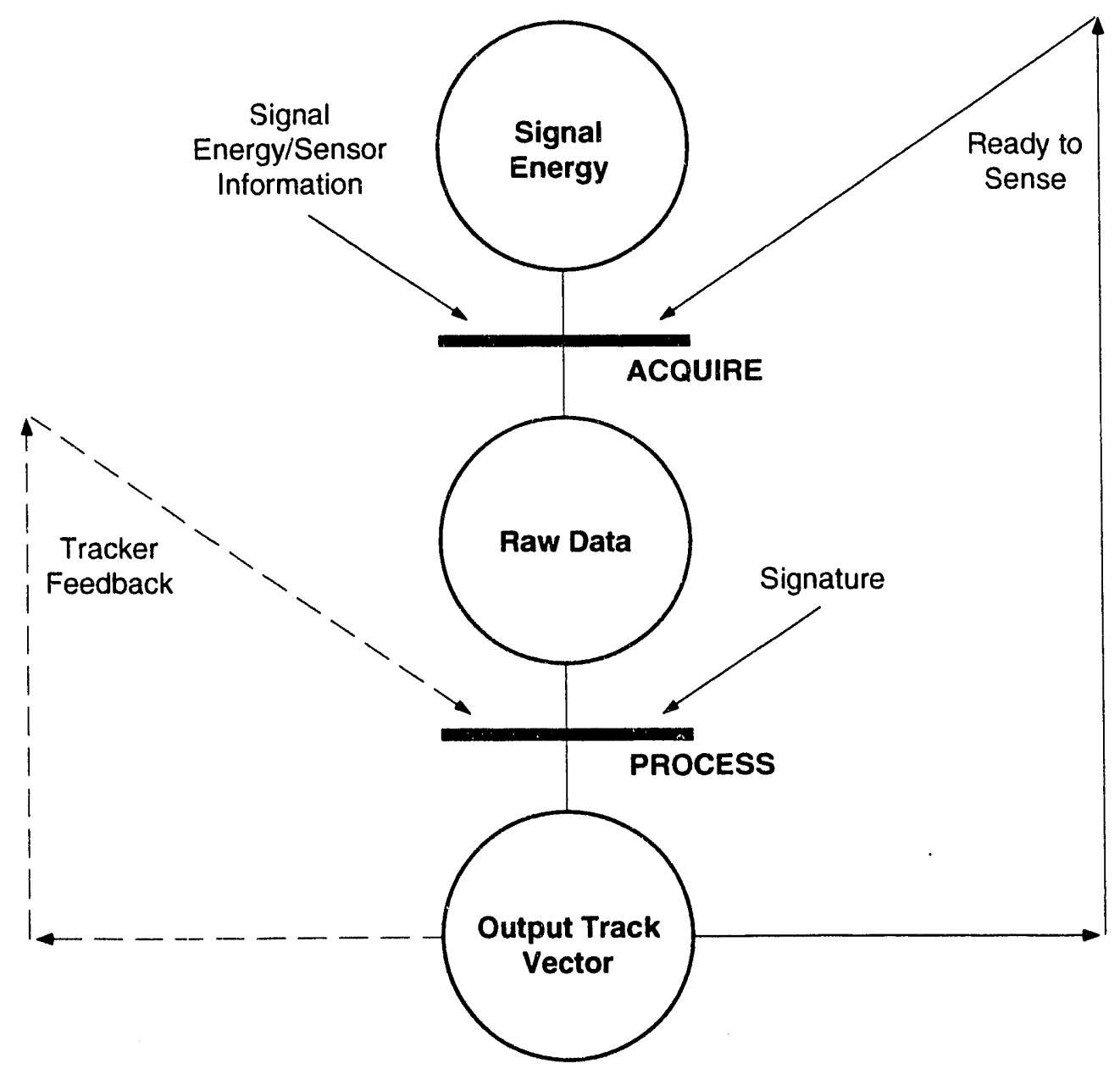

FIGURE 3 Formal Structure, Level 1

At level 2, the symmetry of the ACQUIRE and PROCESS subfunctions becomes more evident (see Figures 4 and 5). In the ACQUIRE subfunction, the physics of the sensor mapping of the signal energy from the environment onto the sensor is coupled with sensor response, sensor distortion, and sensor noise. These activities are performed simultaneously as part of the ACQUIRE subfunction but have been decomposed in this way to mirror the PROCESS subfunction, which attempts to invert each of these steps. The decomposition of ACQUIRE is not unique. In general, however, this decomposition is accurate if the sensor response, sensor distortion, and sensor noise have a linear response, in which case the superposition theorem allows for the decomposition. If the responses are nonlinear, more care must be taken in modeling the nonlinear interaction among sensor response, sensor distortion, and sensor noise.

Table 1 shows how the ACQUIRE and PROCESS subfunctions act as mirrors in level 2. Although this inversion of ACQUIRE by PROCESS is not true in every sensor in the same way, all sensors use this general inversion process (depending on the complexity of the PROCESS subfunction) to extract relevant information and the required fidelity of the output 


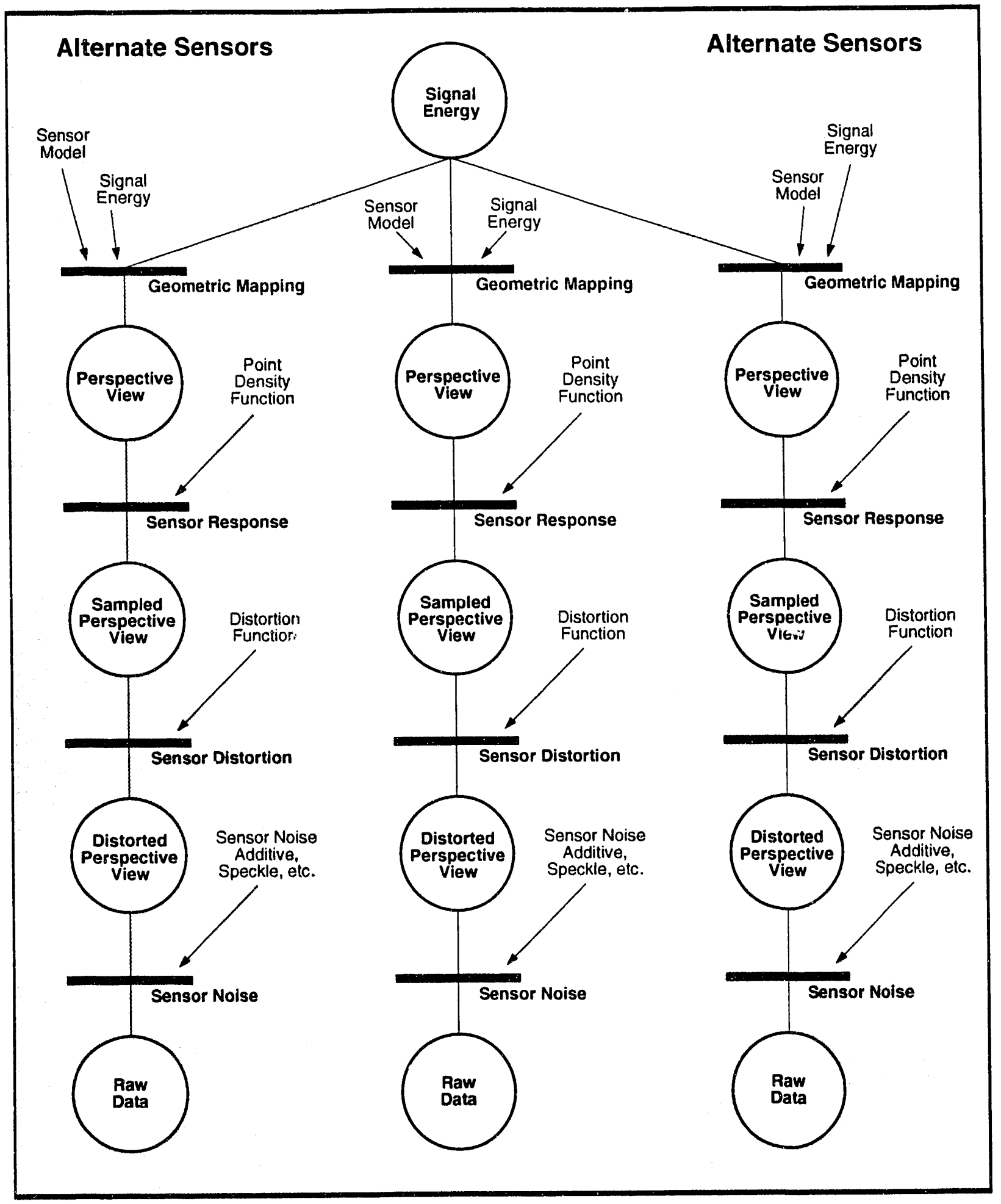

FIGURE 4 Formal Structure, Level 2: ACQUIRE 


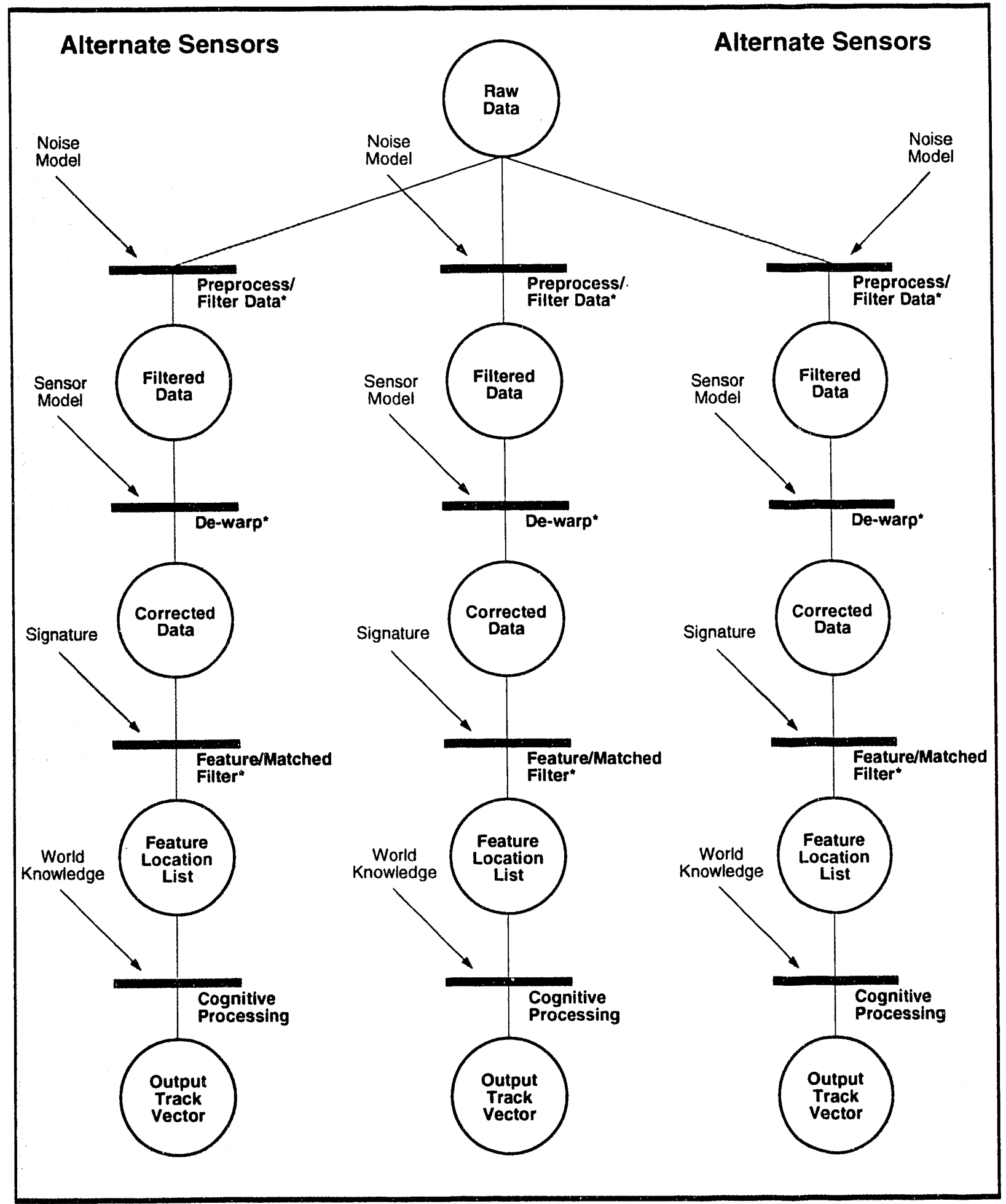

"Could be a null operator.

\section{FIGURE 5 Formal Structure, Level 2: PROCESS}




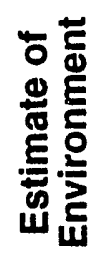
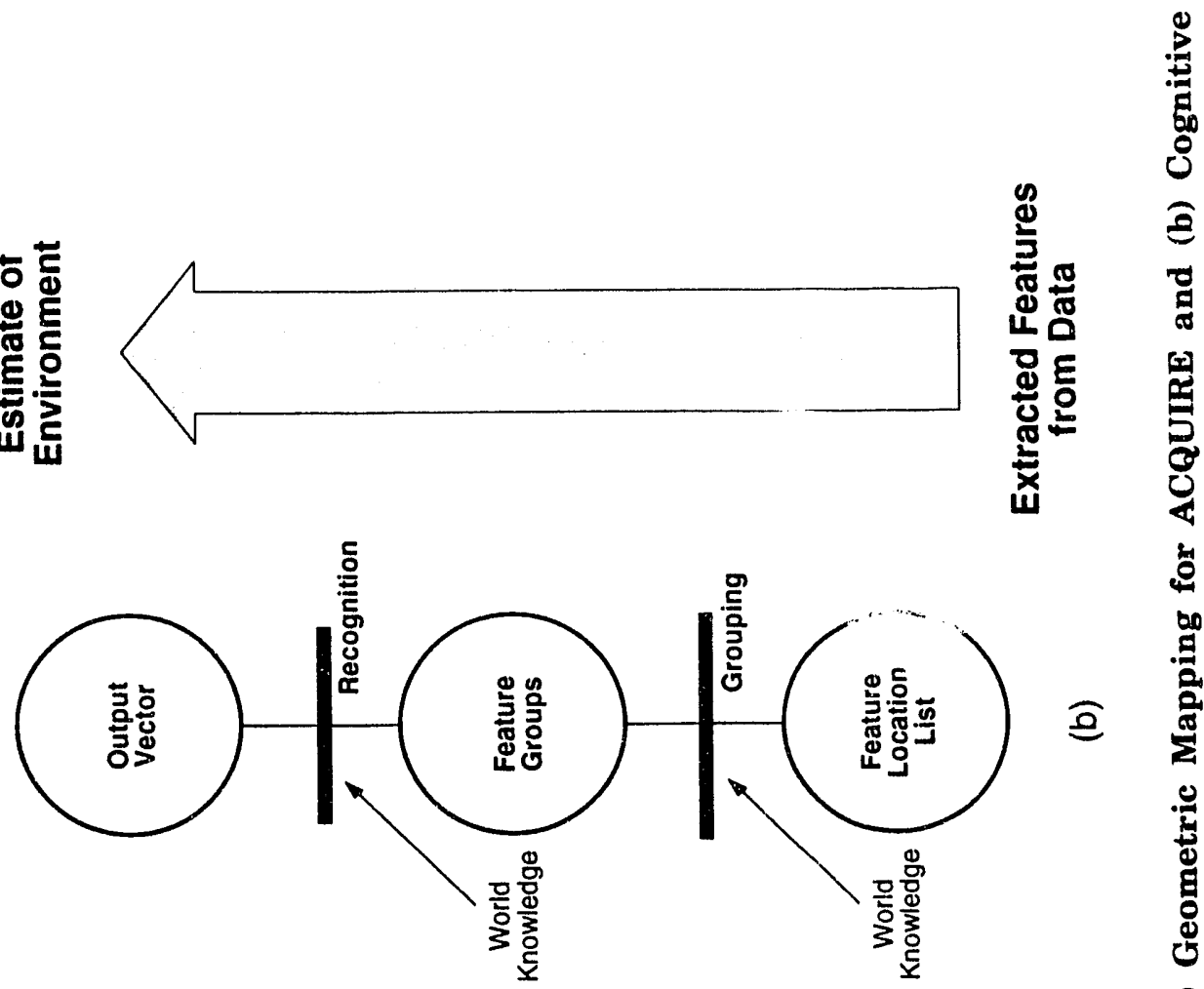

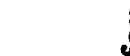



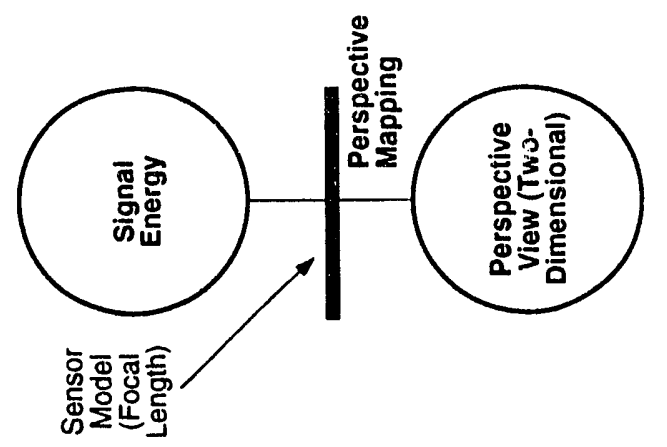

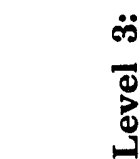

(1)

ํㅗㄴ

क

“ํํㄹ

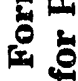

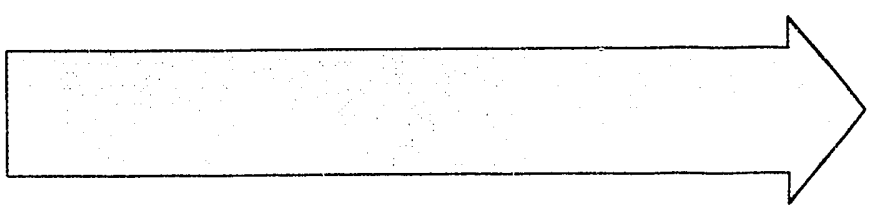

我景 

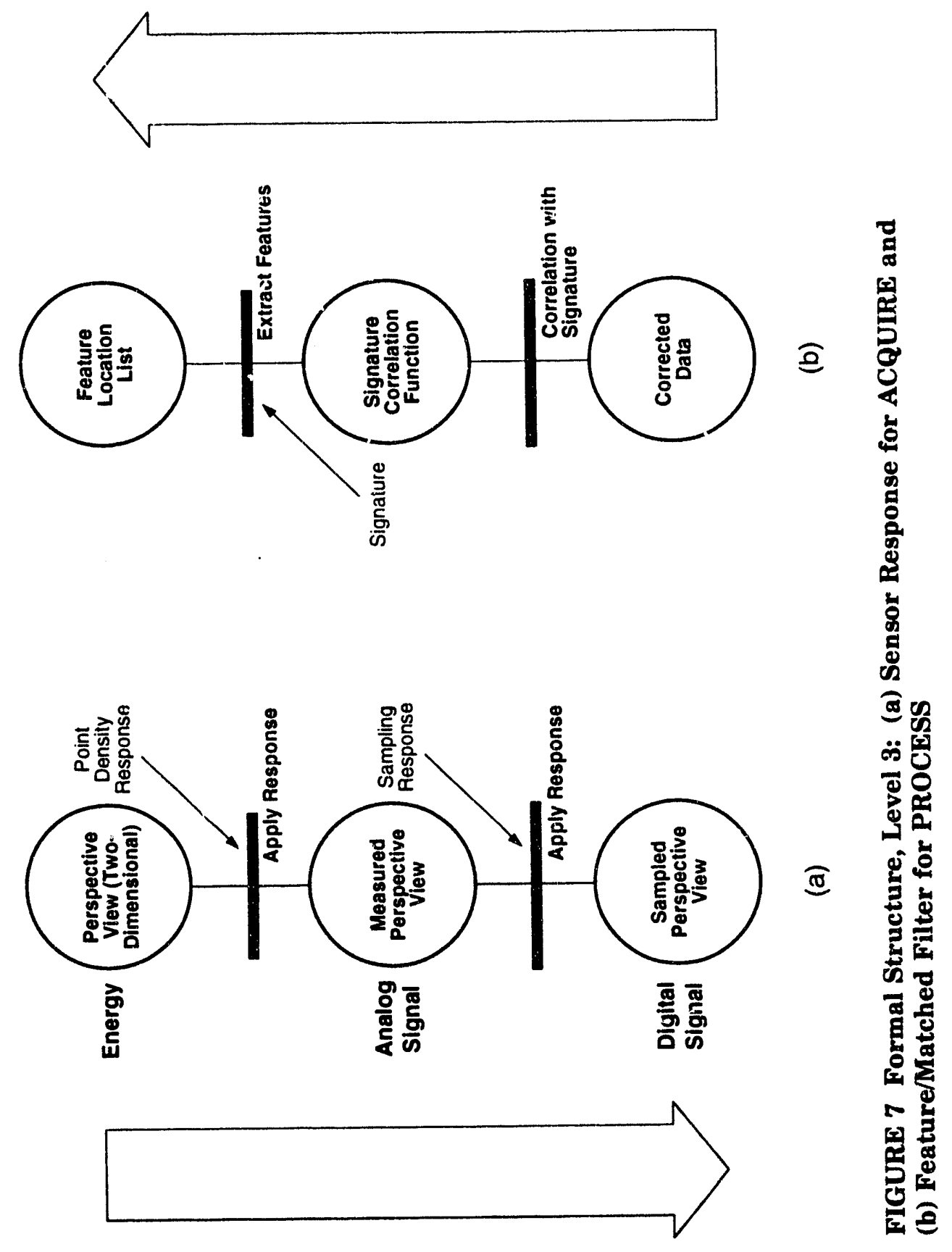


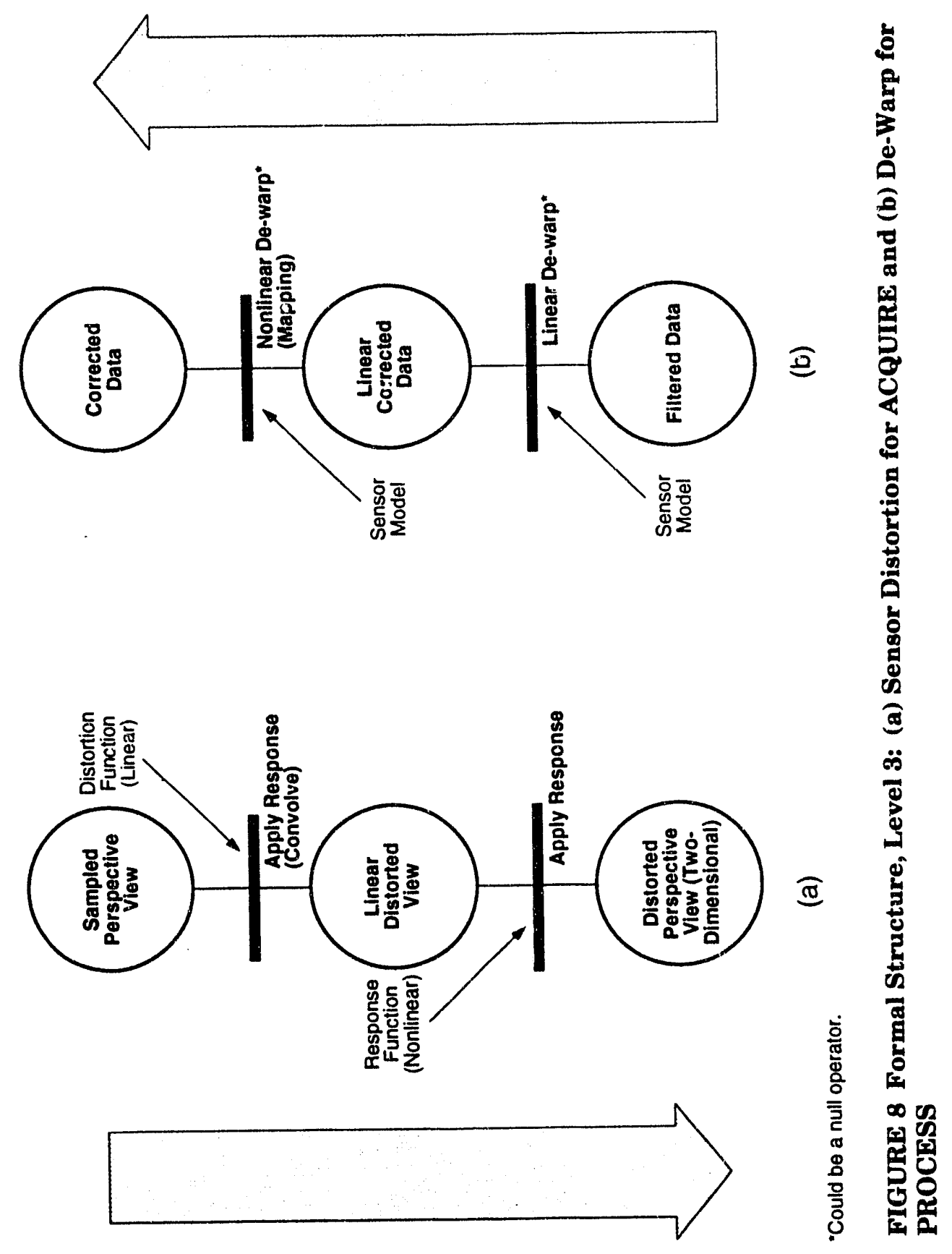




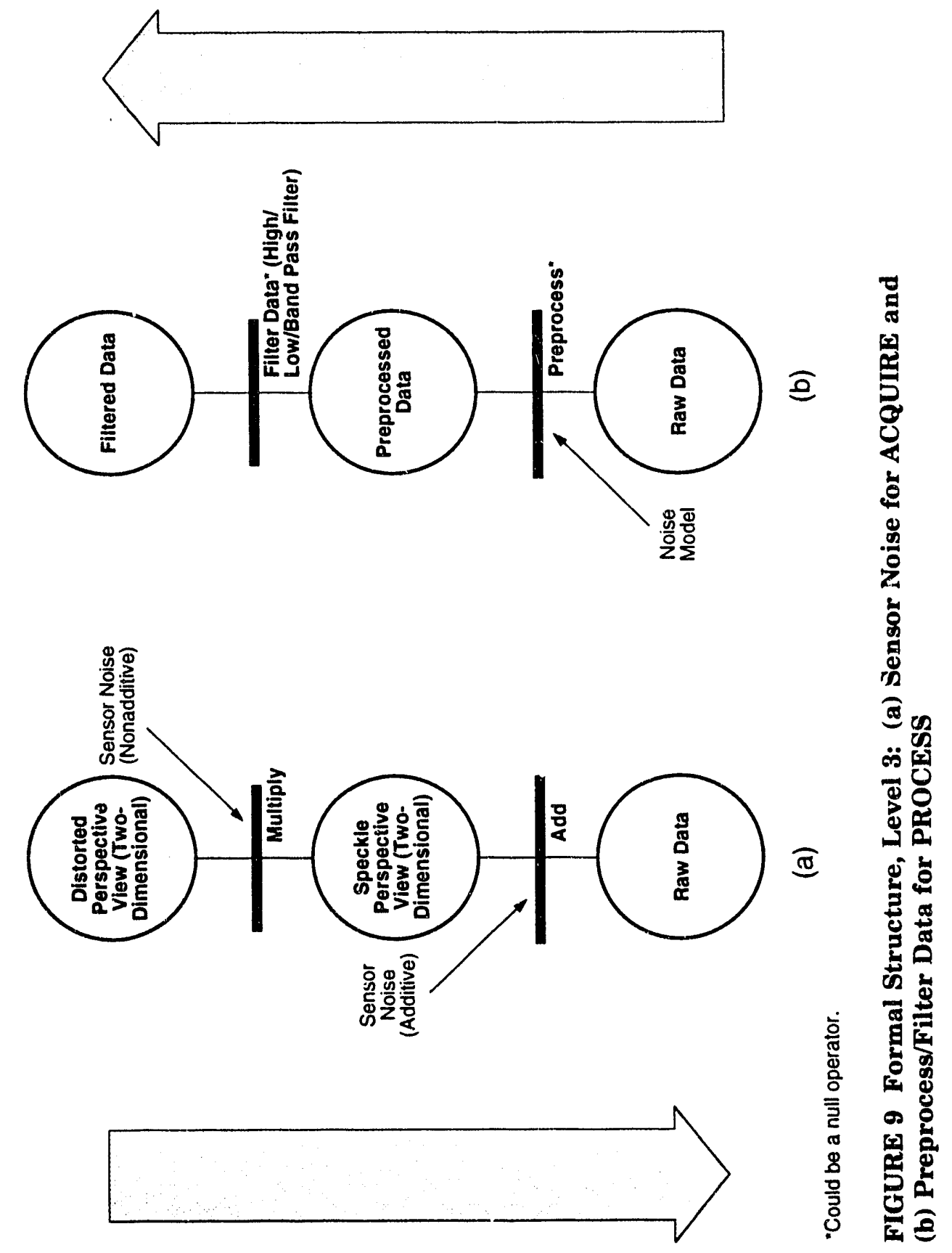


TABLE 1 Comparison of the ACQUIRE and PROCESS Subfunctions

\begin{tabular}{ll}
\hline \multicolumn{1}{c}{ ACQUIRE } & \multicolumn{1}{c}{ PROCESS } \\
\hline Sensor noise & Filtering \\
Sensor distortion & De-warping \\
Sensor response & Feature/mátshed filtering \\
Sensor mapping & Cognitive processing \\
\hline
\end{tabular}

track vector. Thus, one can trade the cost of the PROCESS subfunction with fidelity. Similarly, one can trade the cost of sensor complexity with fidelity.

At level 2, multiple sensors can be included. Using such a configuration allows an analysis of the fault-tolerant aspects of the SENSE function. Two types of fault tolerance are needed because two types of failure can occur:

- A single sensor fails to function. Redundancy of sensors and a voting system could provide fault tolerance in this type of failure. In particular, on the basis of a voting or a Byzantine Generals strategy, many parallel ACQUIRE subfunctions could be used to improve the system's single point of failure (Lamport et al. 1982).

- The sensor fails to detect. Redundancy of sensors does not provide fault tolerance in this type of failure, but sensor fusion (different types of sensors) will provide fault tolerance if the sensors' response functions are independent and the signature of the target is not correlated among the sensor classes.

Level 3 further decomposes the structure (see Figures 6-9). For the ACQUIRE "grandchildren," the details of the specific sensor performance become critical. For the PROCESS grandchildren, the inverse functionality of the ACQUIRE functionality is preserved. 


\section{USE OF THE HIERARCHICAL DECOMPOSITION}

The hierarchical functional decomposition of SENSE is used to investigate the functionality of false alarms and missed detection. Table 2 shows a representation of the transitions and their relationships to false alarms and missed detections.

Although the properties of false alarms and missed detections are not unique, they play a fundamentally important role in the GPALS system. In the best case, false alarms involve identification of nonexistent targets; while such identification is not directly harmful, it does consume resources that could be used more effectively for tracking and eliminating real targets. In the worst case, false alarms can indicate that nontargets are incorrectly identified as targets. Attempts to eliminate such targets can have fatal results.

Flow net representation is also used to translate the SENSE architecture into a formal specification on the basis of first-order predicate calculus. The formal specification can be used with an automated reasoning program such as OTTER (McCune 1990) to address such issues as single point of failure and data dependency. 
TABLE 2 Properties of Transition: False Alarms and Missed Detections for Levels 0, 1, and 2

\begin{tabular}{|c|c|c|c|}
\hline Level & Transitions & False Alarms & Missed Detections \\
\hline 0 & SENSE & $\begin{array}{l}\text { Target is detected when none } \\
\text { is present }\end{array}$ & $\begin{array}{l}\text { No target is detected when } \\
\text { one is present }\end{array}$ \\
\hline 1 & ACQUIRE & $\begin{array}{l}\text { Decoys and similar target } \\
\text { signatures are present. }\end{array}$ & $\begin{array}{l}\text { Stealthy, beyond resolution } \\
\text { of sensor, and low } \\
\text { observables are present }\end{array}$ \\
\hline & PROCESS & $\begin{array}{l}\text { Processing concentrates } \\
\text { signal energy in target } \\
\text { signature band }\end{array}$ & $\begin{array}{l}\text { Processing spreads signal } \\
\text { energy outside target } \\
\text { signature band }\end{array}$ \\
\hline 2 & Geometric mapping & $\begin{array}{l}\text { Nontarget signature is } \\
\text { mapped into signature band }\end{array}$ & $\begin{array}{l}\text { Signature is distorted outside } \\
\text { recognition thresholds }\end{array}$ \\
\hline & Sensor response & $\begin{array}{l}\text { Sensor responds to decoy or } \\
\text { ambient signals }\end{array}$ & $\begin{array}{l}\text { Sensor does not respond } \\
\text { because of sensitivity of } \\
\text { the sensor }\end{array}$ \\
\hline & Sensor distortion & $\begin{array}{l}\text { Nonsignature signal energy } \\
\text { is distorted into signal } \\
\text { signature energy }\end{array}$ & $\begin{array}{l}\text { Sensor distorts signal outside } \\
\text { signature thresholds }\end{array}$ \\
\hline & Sensor noise & $\begin{array}{l}\text { Random noise produces } \\
\text { signature }\end{array}$ & $\begin{array}{l}\text { Random noise obscures } \\
\text { signature }\end{array}$ \\
\hline & Preprocess/filter data & $\begin{array}{l}\text { Energy is filtered into target } \\
\text { signature bands }\end{array}$ & $\begin{array}{l}\text { Target signature is filtered } \\
\text { out }\end{array}$ \\
\hline & De-warp & $\begin{array}{l}\text { Energy is warped in } 0 \text { target } \\
\text { signature bands }\end{array}$ & $\begin{array}{l}\text { Target signature is removed } \\
\text { from signal }\end{array}$ \\
\hline & $\begin{array}{l}\text { Feature/matched } \\
\text { flter }\end{array}$ & $\begin{array}{l}\text { Signature model is too loose } \\
\text { (signal range is too broad) }\end{array}$ & $\begin{array}{l}\text { Signature model is too tight } \\
\text { (signal range is too narrow) }\end{array}$ \\
\hline & Cognitive processing & $\begin{array}{l}\text { A nontarget is mistaken for a } \\
\text { target (threshold is too low) }\end{array}$ & $\begin{array}{l}\text { Target cannot be identified } \\
\text { (threshold is too high) }\end{array}$ \\
\hline
\end{tabular}




\section{SUMMARY AND CONCLUSIONS}

This report developed a hierarchical functional decomposition of the SENSE function of the sense-plan-execute triad. The following conclusions are based on the preliminary analysis of this decomposition:

- The addition of multiple sensors ensures that no single point of failure will cause a system breakdown as long as the assumption about the independence of the sensors is valid. Thus, diverse sensors provide resistance to design errors, and redundancy provides resistance to operational errors.

- The properties of false alarms and missed detections are critically important to the functionality of SENSE in the GPALS system.

- The processes in the ACQUIRE and PROCESS subfunctions are local (in time and space). Thus, data can be traced through these subfunctions to determine independent and dependent information. This interdependence is partly based on the bandwidth of the sensors and the effective bandwidth (smearing) of the process algorithms. Similarly, at the leaf level, the effects of inplemerting the data dependency issue can be investigated through use of the software. 


\section{FUTURE WORK}

Four specific projects are targeted for future investigation:

- Expand the functional decomposition of the SENSE function for selected leaves down to the code level.

- Use an automated reasoning system to study the formal system in terms of data dependency and fault tolerance issues.

- Explore the use of empirical testing for a performance database of the SENSE function.

- Perform a detailed sensor-specific hierarchical functional decomposition for an appropriate class of sensors, such as synthetic aperture radar or infrared sensors. 


\section{REFERENCES}

Chisholm, G., 1992, "A Methodology for Complexity Management," presented at the Trusted Computer Resources Symposium, Strategic Defense Initiative Organization, U.S. Department of Defense, Aug. 25-26; available from J.K. MacLaury, Dynamics Research Corp., Arlington, Va.

Lamport, L., et al., 1982, "The Byzantine Generals Problem," ACM Transactions on Programming Languages and Systems 4(3):382-401.

McCune, W.W., 1990, OTTER 2.0 Users Guide, report ANL-90/9, Argonne National Laboratory, Argonne, Ill., March.

Peterson, J.L., 1981, Petri Net Theory and the Modeling of Systems, Prentice-Hall, Inc., Englewood Cliffs, N.J.

Winter, V.L., et al., 1991, A Formal Model for Verification of Abstract Properties, report ANL-92/10, Argonne National Laboratory, Argonne, Ill., April. 

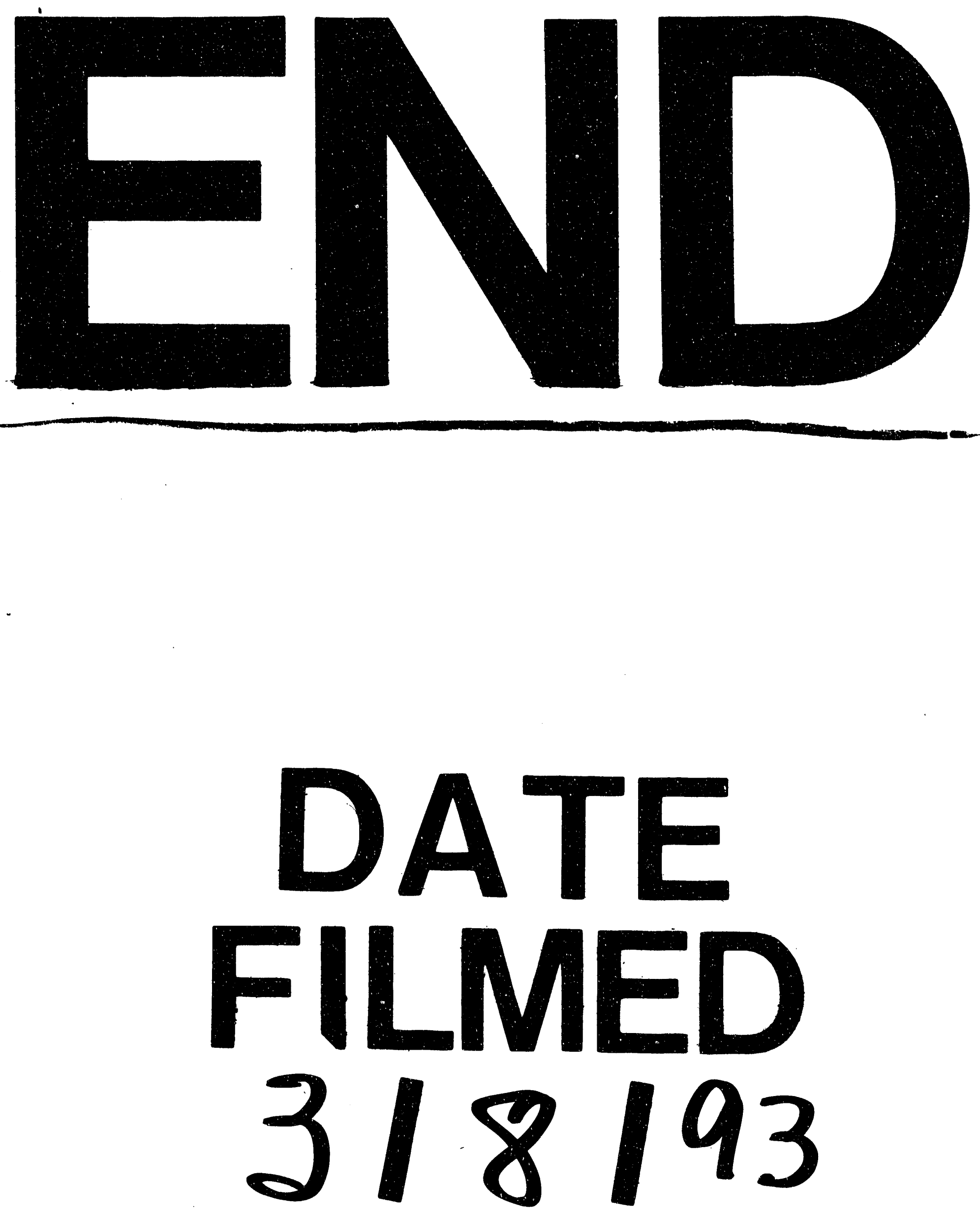
